\section{WORDWATCH}

\section{Embiggen}

In a case of theoretical physics imitating art, 'embiggen', first coined by The Simpsons character Jebediah Springfield, has now been used in a paper on string theory by Stanford University's Shamit Kachru. In case you need a definition, it means 'to grow or expand'. Obviously.

\section{SCORECARD}

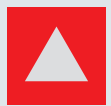

Regret-free tattoos The pain of removing that no-longer-hip

tattoo could soon be a thing of the past, with the advent of ink-filled polymer capsules that can be injected under the skin, and later ruptured to disperse the ink.

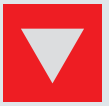

\section{Virtual gambling} Administrators of the booming virtual world Second Life have forbidden all casino games, in line with the US blanket ban on online gambling.

\section{ZOO NEWS}

\section{Bear minimum}

To feed the public's (and our) obsession with Knut, keepers at Berlin Zoo have announced that they are putting the cub on a diet. Bizarrely, the world's most famous polar bear was previously allowed to eat croissants, but not any more

- he's

looking quite chubby at around 60 kilograms.

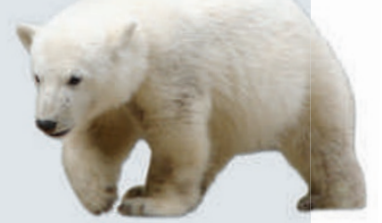

\section{GOOD REASONS...}

\section{...to have sex}

According to research in this month's Archives of Sexual Behavior, there are a staggering 237 reasons why people might choose to mate. Here is a brief selection.

1 The most common: "I was attracted to the person."

2 The prosaic: "It seemed like good exercise."

3 And the refreshingly honest: "The opportunity presented itself."

Sources: Scientific American, The Guardian, The Times, Der Spiegel, New York Times

\title{
Academic accused of living on borrowed lines
}

A shockwave could be about to hit the normally tranquil waters of social science. A German economist, specializing in environmental science and technology, has allegedly committed serial plagiarism and invented academic affiliations going back decades. The case should act as a warning sign to editors about how widespread plagiarism and deception may be, experts say.

Events may only now be catching up with Hans Werner Gottinger, 63, who is drifting into retirement in the town of Ingolstadt, Germany. This week the journal Research Policy is set to retract a 1993 paper by Gottinger, which analysed demand for spin-off technologies from Ronald Reagan's Strategic Defense Initiative. An accompanying editorial explains that two referees concluded that the article substantially plagiarized a paper published in 1980 in the Journal of Business by Frank Bass, then an economist at Purdue University in West Lafayette, Indiana. The "Plagiarism may be much more common than we previously thought." by economist Zhiqi Chen of Carleton University in Ottawa, Canada.

"I was shocked and saddened that someone in my profession could do something like that," Chen says. For his part, Gottinger says that the papers were "clearly designed as review papers and did not claim any novel ideas".

Martin then contacted Gottinger's supposed employer, Maastricht University in the Netherlands, about the cases. But the university says that Gottinger has never been appointed or affiliated with it in any capacity. "We have written to Gottinger and asked him to remove from the web all reference to an affiliation with our university," says university spokeswoman Jeanine Hermans. Gottinger told Nature that the affiliation was a "misguided muddling" of other institutes in Maastricht with which he claims to have been affiliated, and says he has contacted all the web pages he can think of to correct matters. editorial also profiles other cases of plagiarism.

Gottinger claims that he has "only scant recollection" of events so long in the past, but insists that he did not intend to plagiarize. He adds that he has "sincerely apologized" for any misunderstandings.

Problems with his paper came to the journal editors' attention in June, when a student noted that whole paragraphs and strings of complex mathematical equations in the Bass paperwhich analysed demand for consumer-durable technologies - had been repeated almost exactly in Gottinger's paper. Gottinger did not acknowledge the Bass paper in his work.

Further investigations by one of the journal editors, Ben Martin, an expert in science policy at the University of Sussex in Brighton, UK, revealed that this was not the first such case. In 1999, the editors of the economics journal Kyklos had withdrawn a 1996 paper by Gottinger after finding that it had plagiarized a 1992 paper in the journal Economics of Innovation and New Technology. And by googling various strings of text from half a dozen other Gottinger papers, Martin identified yet another case - a 2002 paper by Gottinger about an economic model of global warming in the International Journal of Global Energy Issues, in which whole sections were remarkably similar to a 1997 article in the Journal of Environmental Economics and Management,
Nature has checked other claims made by Gottinger, including membership of professional societies and editorships of several influential journals. We failed to confirm membership of any of the societies, and some of the journals deny he was ever an editor with advisory board of Technology Forecasting and Social Change in 2003, after the journal became aware of the issue of the Kyklos plagiarism.

\section{A chequered career}

Gottinger started out in 1973 as a faculty member at the University of Bielefeld in northern Germany, until his resignation in 1980. His co-worker Peter Weingart remembers him as someone strongly orientated towards mathematical approaches, which was unusual in a sociology department. "He was considered highly intelligent but reserved," Weingart says.

In 1979, Gottinger was sacked from the GSF national research centre in Munich because of deception relating to a European Union grant application. From the mid-1980s on, he started to list Maastricht University as his academic affiliation on papers. In 1988 he was appointed as director of the Fraunhofer Institute for Technological Trend Analysis in Euskirchen near Bonn. He says he left over professional differences of opinion; current director Uwe Wiemken says the appointment "didn't end peacefully". them. He was, however, removed from the 


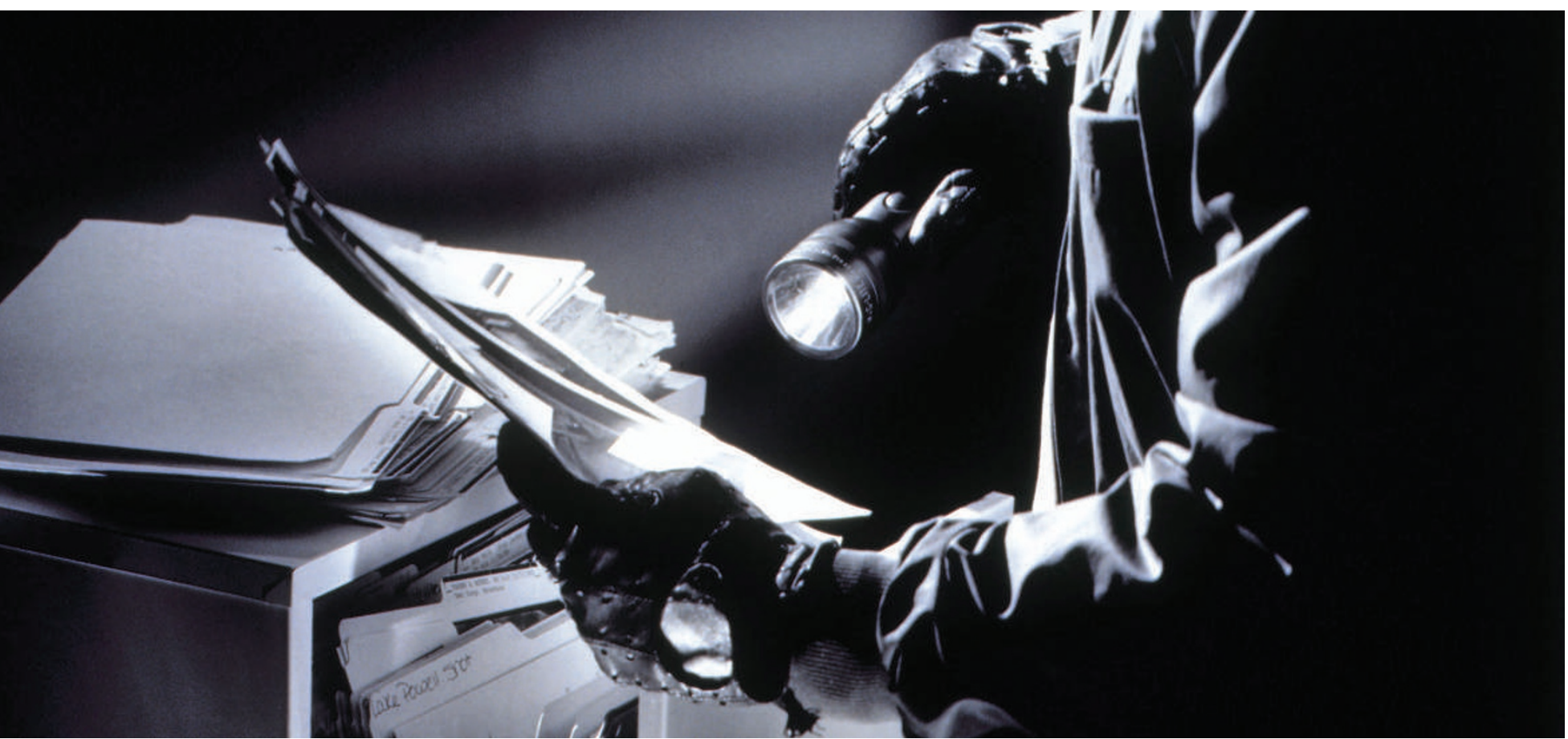

Duplicated text alerted editors of the journal Research Policy to a wider web of deception.

Gottinger then moved abroad, working at the Oxford Institute for Energy Studies in the United Kingdom, and also at Norway's Centre for International Climate and Environmental Research in Oslo. In the mid-1990s he was involved with a private business school in the small town of Bad Waldsee in southwest Germany. Over the past decade, Gottinger has held various positions in Japan as well as an appointment at Rensselaer Polytechnic Institute in Troy, New York, that lasted only a matter of weeks. At one point he received a special fellowship from the Carisal Foundation in Salerno, Italy, on the strength of the impressive CV he submitted.

During his career, Gottinger has clocked up more than 100 articles in reputable journals, and was shortlisted for the rectorship of the University of Klagenfurt in Austria in 1995, coming within a whisker of being elected.

Institutions that employed him are reluctant to discuss details of his case. Nature has inves-

\section{Copycat trap}

Plagiarists should beware. The next time they submit a paper to a journal, a red flag may pop up on the editors' screen warning them that the article's word patterns are suspiciously similar to those of a published paper. A pilot of this computer cop, called CrossCheck, was launched on 1 August by CrossRef, a group of 2,046 scholarly publishers.

Commercial software of this kind has been available for some time, but until now subscription firewalls have prevented its use with online literature. CrossCheck is able to access the databases of its member publishers.
Six publishers are taking part in the pilot: the Association for Computing Machinery, BMJ Publishing Group, Elsevier, the Institute of Electrical and Electronics Engineers, Taylor \& Francis, and Wiley-Blackwell. Like a search engine on the web, the program computes the similarity of word strings to yield an originality score. Suspect scores are flagged-up, and it displays similar excerpts of text from different sources. But an editor will need to examine the flagged up papers to confirm plagiarism.

If all goes well, the service could be available as soon as November and other software providers could request access in the future, says Geoffrey Bilder, director of strategic initiatives at CrossRef. Publishers could also get authors to test their papers before submission, which would spread out the work and allow honest authors to check they hadn't inadvertently 'cut and paste' verbatim, says Bilder.

The downside, he notes, is that the program would let hardened plagiarists play the system, by rewording detected passages. "It might just force people to become more sophisticated plagiarists." Declan Butler tigated other affiliations claimed by Gottinger at different times and found many to be inaccurate - including Osaka University in Japan, which Gottinger attributes to a "sloppy misrepresentation" of claimed affiliations with two other institutes in the city.

So how could he have got away with so much alleged deception for so long? Detecting plagiarism is not easy (see 'Copycat trap'). Martin also speculates that the highly mathematical nature of Gottinger's work, unusual in the social sciences, may have been tough on referees. "It's frightening - it suggests plagiarism may be much more common than we previously thought," says Martin. "It undermines the basis of trust we have - and must continue to have - in our academic literature and our research community."

Most scientists who had contact with Gottinger refer to him as a lone operator only occasionally did he have a co-author. One of these was Peter Weimann, now a professor at the University of Applied Sciences in Berlin. (None of his co-authored papers is suspected of having plagiarized work.) Weimann says that Gottinger was "hard to work with because he was not very communicative".

In a final twist, Martin has found that one of Gottinger's papers (in 1992) may itself have been plagiarized - in 2005, by an academic from Zimbabwe.

Alison Abbott, with additional reporting by David Cyranoski, Emiliano Feresin and Carina Lenotti 


\section{Correction}

The News story 'Academic accused of living on borrowed lines' (Nature 448, 632-633; 2007)

incorrectly identified Peter Weingart as a

co-worker of Hans-Werner Gottinger. Weingart

did not work on any research projects with

Gottinger, but was simply another member of

the department of sociology at the University of

Bielefeld at the time. 